\title{
Laser edge forming to increase the bending radius in hemming
}

\author{
Peer Woizeschke ${ }^{1, *}$, Lukas Heinrich ${ }^{1}$, Philip Eichner ${ }^{2,3}$ \\ ${ }^{1}$ BIAS - Bremer Institut für angewandte Strahltechnik GmbH, Klagenfurter Str. 5, 28359 Bremen, Germany \\ ${ }^{2}$ University of Bremen, Klagenfurter Str. 5, 28359 Bremen, Germany \\ ${ }^{3}$ Present address: VEMAG Maschinenbau GmbH Verden, Weserstraße 32, 27283 Verden (Aller), Germany
}

\begin{abstract}
Hemming can be used, for example, to join dissimilar materials which cannot be welded by conventional laser or arc based processes. A critical value in hemming is the ratio of outer sheet bending radius and outer sheet thickness because cracks can occur in outer sheets with low ductility due to a small bending radius. In this study, a novel approach is introduced for increasing the bending radius by laser based edge forming. The laser beam melts the edge of the inner sheet prior to the hemming process. In laser edge forming, the edge thickness increases due to the surface tension of the melt. The edge cross-section has typically a nearly circular shape after solidification. Two laser beam irradiation strategies were investigated. In case of the first strategy, a defocused laser beam was applied. The second strategy combined a focused laser beam resulting in the formation of a vapor capillary (keyhole) with sinusoidal beam oscillation transversal to the sheet edge. The results show that the position of the cylindrical edge cross-section according to the sheet plane could be affected by the applied irradiation strategy. The needed laser power was significantly lower when using a focused laser beam due to the deep penetration effect. The potential of the laser edge forming technique for crack-free hemming processes was demonstrated with $1 \mathrm{~mm}$ thick aluminum alloy sheets by carrying out stripe tests.
\end{abstract}

Keywords: Joining, Metal Forming, Laser

\section{Introduction}

Hemming can be applied as process to increase the stiffness of a sheet edge or to eliminate the sharpness of an edge on the one hand. On the other hand, hemming can be applied for joining or assembling two sheets by folding an outer sheet around an inner sheet. The hemming joining technique has potential to replace partially the spot welding in the production of hollow sections for car body structures in case of certain (also dissimilar) material combinations, see Figure 1a and 1b. A main challenge in hemming is to avoid damages in form of cracks in the outer sheet being non-acceptable in part manufacturing [1]. Especially in case of materials with low ductility, the bending of the outer sheet can result in critical tensile strains [2]. In order to enhance the bending ability, for example in case of aluminum alloys, process and tool design modifications were analyzed by experiments and simulations and summarized by trend-lines [3] and a new flanging operation to deliver additional metal into the bending zone [4] as well as an electromagnetic forming (EMF) technology [2] were developed. In case of highstrength steels with low ductility, crack-free hemming was achieved by hemming using a punch with stopper [5]. In doing so, the zone of the outer sheet with high tensile stress is additionally compressed. A main parameter

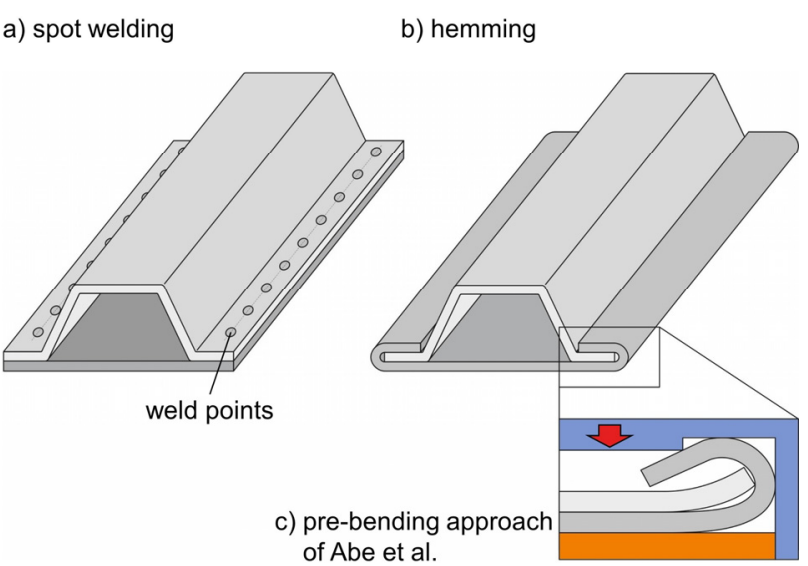

Fig. 1. (a) Sketch of a typical spot welded hollow section; (b) sketch of a hemmed variant of the hollow section and (c) schematic description of the approach of Abe et al. according to [7] for using a pre-bent inner sheet to increase the bending radius of the outer sheet.

regarding the critical bending conditions is the ratio of the bending radius of the outer sheet and its sheet thickness. For the application of hemming in car manufacturing, a

\footnotetext{
* Corresponding author: woizeschke@bias.de
} 
concept was invented [6] in which a groove is inserted on the inside of the outer sheet to improve the bending process. Basically, the bending radius is determined in conventional hemming processes by the inner sheet thickness. In this regard, Abe et al. presented an approach at which a pre-bending of the inner sheet was used to increase the bending radius of the outer sheet [7], see sketch in Figure 1c. The process enabled the crack-free production of ultra-high strength steel hollow parts by 3 -stage hemming [7]. In case of classical hemming of high-strength steel sheets cracks occurred [5].

The results of Abe et al. motivated the work presented in this paper. The investigated novel concept is based on appropriately modifying the edge of the inner sheet by laser melting. Laser beam edge melting might be applicable to form advantageously the edge of the inner sheet. Vollertsen et al. developed the "free form heading" laser melting process for wires/rods to reduce the number of steps of forming processes [8]. A laser beam melts the rod end during the process to produce preforms with a drop-like shape and increased diameter due to the surface tension of the molten material. Woizeschke et al. transferred the process approach to sheet edges and demonstrated the fundamental feasibility of producing cylindrical forms along sheet or foil edges by laser melting processes [9]. In principle, different laser beam irradiation strategies are applicable [9]. Figure 2 demonstrates the laser edge forming by using a defocused laser spot which is guided on the sheet surface and moved along the sheet edge [9].

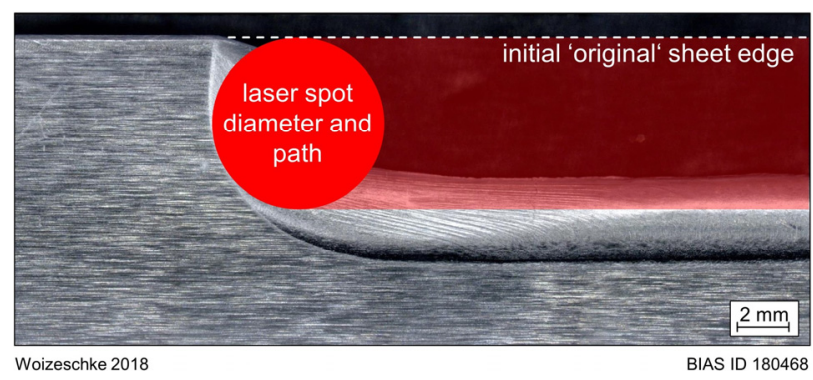

Fig. 2. Example for laser edge forming by using a defocused laser spot according to [9].

In this study, laser based edge forming shall be investigated to enable the precise increase of the bending radius in hemming to produce crack-free joints in case of materials with low ductility. Two strategies of laser edge forming, a heat conduction based variant with a defocused large laser spot on the workpiece (named "defocused" strategy in this study) and a deep penetration based variant with a focused laser beam on the workpiece superimposed by a spatial transversal beam oscillation (named "oscillation" strategy), shall be analyzed regarding advantages and disadvantages with respect to the process behaviors and the resulted edge forms.

\section{Materials and methods}

\subsection{Material}

The experiments of this study were carried out with sheets of the aluminum alloy EN AW 6082 (AlSi1MgMn) in the heat treatment condition T4. The base material thickness was $1 \mathrm{~mm}$. The specimens with the dimension of $160 \mathrm{~mm} \times 100 \mathrm{~mm}$ were shear cut and the edges were milled to generate reproducible conditions. The milled edges are called 'original' or 'conventional' edges in contrast to the 'laser formed' edges in this study.

\subsection{Laser setup}

A disk laser (wavelength of $1030 \mathrm{~nm}$; beam quality of $8 \mathrm{~mm}$ mrad; TruDisk 8002) was used as laser source for the melting processes. A gantry system (company Föhrenbach) was equipped with a laser processing optic to perform the laser edge forming. The laser beam was guided to the laser head by a fiber with a core diameter of $200 \mu \mathrm{m}$. The focal lengths of collimation as well as focusing were $200 \mathrm{~mm}$ and, thus, the resulting laser focal diameter was $0.2 \mathrm{~mm}$. A scanning system (DC-scanner ILV-0205; ILV) for spatial beam modulation was mounted on the laser head to enable the beam oscillation transversal to the main process direction which was parallel oriented to the sheet edge. The scanning system allowed the application of sinusoidal beam oscillation. The maximum amplitude depended on the oscillation frequency. Argon was applied as shielding gas for the melt pool during the laser melting processes.

\subsection{Irradiation strategies}

Two irradiation strategies were carried out to produce suitable edge forms for hemming processes. In case of the "defocused" irradiation strategy, a defocused laser beam with a comparatively large laser spot diameter on the workpiece was used to melt the sheet edge without any additional beam oscillation. In case of the "oscillation" irradiation strategy, the main movement of the laser head was superimposed by the transversal beam oscillation. Thus, the laser beam focus, which was positioned on the workpiece surface at this strategy, followed a sinusoidal path along the edge. The process parameters of the experiments in this study are listed in Table 1.

\subsection{Measuring methods}

The thickness of the laser based thickened/formed sheet edge was measured at seven positions along the edge in $20 \mathrm{~mm}$ intervals by using a digital caliper. The starts and the ends of the edge are not considered in this study. The averages and standard deviations in the analysis are based on 70 samples per strategy.

The metallographic analysis was performed by crosssectional polishes of the laser formed edges. The polishes were electrolytically etched according to the etching parameters which are given in Table 2. A sequence of abrasives up to grit 1200 was used before etching. 
Micrographs of the prepared polishes were taken by a microscope under polarized light.

Table 1. Process parameters for both irradiation strategies.

\begin{tabular}{|c|c|c|}
\hline $\begin{array}{l}\text { process } \\
\text { parameter }\end{array}$ & $\begin{array}{l}\text { irradiation } \\
\text { strategy } \\
\text { "defocused" }\end{array}$ & $\begin{array}{l}\text { irradiation strategy } \\
\text { "oscillation" }\end{array}$ \\
\hline $\begin{array}{l}\text { main process } \\
\text { direction }\end{array}$ & $\begin{array}{l}\text { parallel to the } \\
\text { sheet edge }\end{array}$ & $\begin{array}{l}\text { parallel to the sheet } \\
\text { edge }\end{array}$ \\
\hline $\begin{array}{l}\text { superimposed } \\
\text { laser beam } \\
\text { movement }\end{array}$ & - & $\begin{array}{l}\text { sinusoidal oscillation } \\
\text { transversal to the } \\
\text { main process } \\
\text { direction }\end{array}$ \\
\hline focal plane & $\begin{array}{l}+16 \mathrm{~mm} \text { above } \\
\text { the workpiece }\end{array}$ & $\begin{array}{c}\text { on the workpiece } \\
\text { surface }\end{array}$ \\
\hline $\begin{array}{l}\text { spot diameter on } \\
\text { the workpiece }\end{array}$ & $6.1 \mathrm{~mm}$ & $0.2 \mathrm{~mm}$ \\
\hline shielding gas & \multicolumn{2}{|c|}{ argon } \\
\hline $\begin{array}{l}\text { opening diameter } \\
\text { of the shielding } \\
\text { gas nozzle }\end{array}$ & \multicolumn{2}{|c|}{$28 \mathrm{~mm}$} \\
\hline shielding gas flow & $201 / \mathrm{min}$ & $301 / \min$ \\
\hline laser output power & $5.5 \mathrm{~kW}$ & $1.1 \mathrm{~kW}$ \\
\hline $\begin{array}{l}\text { main process } \\
\text { speed }\end{array}$ & $0.8 \mathrm{~m} / \mathrm{min}$ & $0.8 \mathrm{~m} / \mathrm{min}$ \\
\hline $\begin{array}{l}\text { oscillation } \\
\text { frequency }\end{array}$ & - & $100 \mathrm{~Hz}$ \\
\hline oscillation width & - & $6.3 \mathrm{~mm}$ \\
\hline $\begin{array}{l}\text { initial waiting } \\
\text { time }\end{array}$ & - & $0.2 \mathrm{~s}$ \\
\hline
\end{tabular}

Table 2. Etching parameters of the cross-section polishes.

\begin{tabular}{|c|c|}
\hline electrolyte & $\begin{array}{c}\text { aqueous solution of 2-percent tetrafluoroboric } \\
\text { acid } \\
\mathrm{HBF}_{4} \text {-solution: } \\
950 \mathrm{ml} \mathrm{H}_{2} \mathrm{O}+38 \mathrm{ml} \mathrm{HBF} 4 \\
\end{array}$ \\
\hline voltage & $25 \mathrm{~V}$ \\
\hline duration & $60 \mathrm{~s}$ \\
\hline flow rate & $10 \mathrm{ml} / \mathrm{min}$ \\
\hline
\end{tabular}

\subsection{Feasibility test}

In order to demonstrate the feasibility of hemming with laser formed inner sheet edges, simple stripe tests have been carried out with $1 \mathrm{~mm}$ thick aluminum sheets. The outer sheet stripe was manually bent around the inner sheet (with and without laser formed edge). After bending the outer sheet was hemmed by pressing it on the base sheet (next to the formed edge). The surfaces of the outer sheets were analyzed with respect to cracks or other defects.

\section{Results}

\subsection{Process observations}

Figure 3 shows snapshots of the laser forming for both strategies during the laser melting processes. The focused oscillating laser beam in case of the "oscillation" strategy generated a highly dynamic process behavior with significant spatter formation (see Figure 4b), whereas no spatters were observed during the process of the "defocused" strategy with a defocused non-oscillated laser beam.
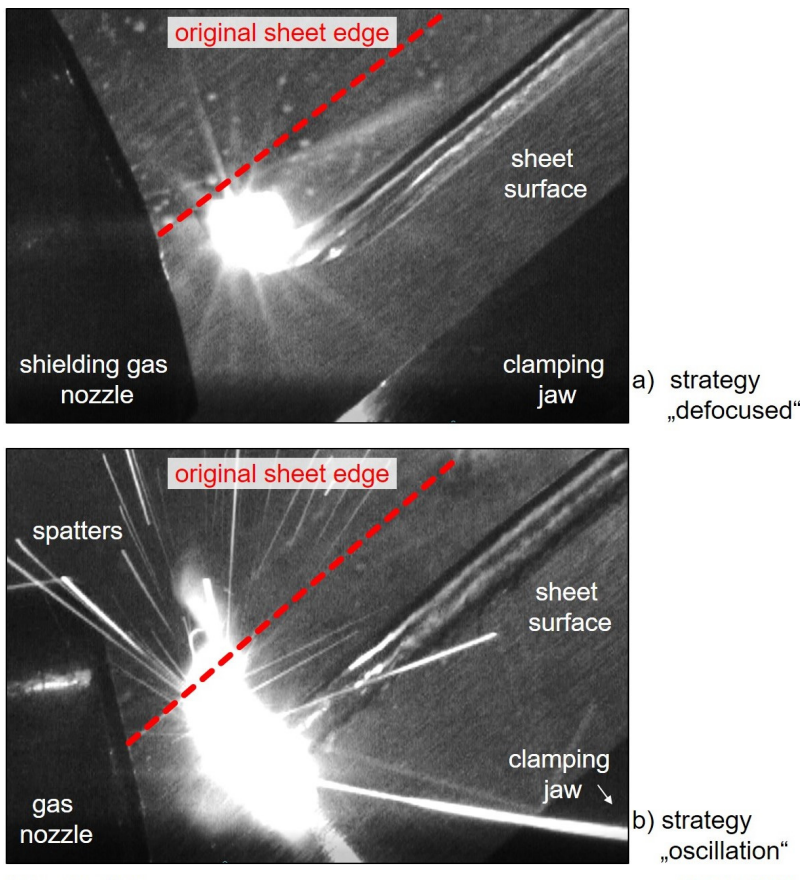

strategy "Oscillation" BIAS ID 180460

Fig. 3. Snapshots during the laser forming processes for (a) the "defocused" strategy and (b) the "oscillation" strategy (red broken lines: original sheet edges before laser melting).

\subsection{Characteristics of the laser formed edges}

The laser formed edges for both strategies are shown by front and side views in Figure 4 and Figure 5. In both cases, no adhering spatters on the sheet surfaces were observed. The measured values of the edge form thickness (diameter) along the edge are plotted for the two strategies in Figure 6 and Figure 7. The averages of the edge form thickness vary along the edges by less than $0.1 \mathrm{~mm}$. The average value of the "defocused" strategy was determined to $3.44 \pm 0.07 \mathrm{~mm}$. In case of the "oscillation" strategy the average is $2.98 \pm 0.08 \mathrm{~mm}$. Both strategies resulted in edge forms with approximately circular cross-section. The center of the form cross-section was below the sheet plane in case of the "defocused" strategy considering that the laser beam was guided on the upper sheet surface, whereas the center was positioned above the sheet plane in case of the "oscillation" strategy, see Figure 8a and Figure 9a. The micrographs of the cross-sections show grain coarsening within the laser formed edges. In contrast to the defocused variant, the laser forming with 
the focused oscillating laser beam produced an area with significantly smaller grains, see Figure $9 \mathrm{c}$. The red dotted lines show a difference in the fusion line orientation.

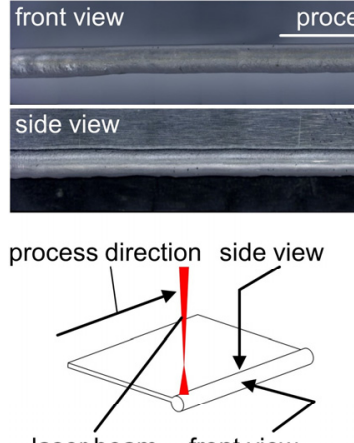

laser beam front view aluminum alloy base sheet thickness laser source disk laser TruDisk 8002 laser output power process speed laser spot diameter focal plane shielding gas flow

Woizeschke 2018

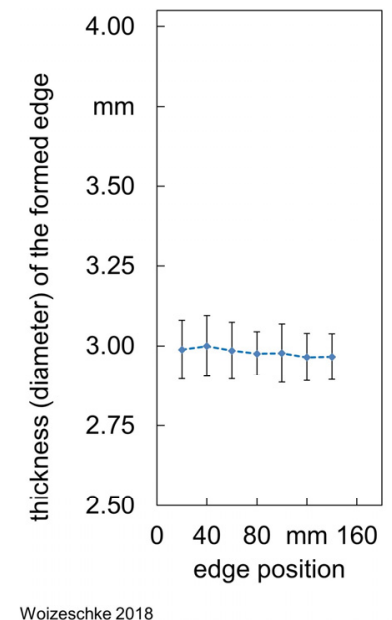

luminum alloy EN AW 6082-T4 base sheet thickness $\quad 1.0 \mathrm{~mm}$ laser source disk laser laser output power $\quad 1100 \mathrm{~W}$ process speed $\quad 0.8 \mathrm{~m} / \mathrm{min}$ focus diameter $\quad 0.2 \mathrm{~mm}$ oscillation frequency $\quad 100 \mathrm{~Hz}$ oscillation width $\quad 6.3 \mathrm{~mm}$ shielding gas flow argon $30 \mathrm{l} / \mathrm{min}$ initial waiting time $\quad 0.4 \mathrm{~s}$ preform thickness $2.98 \pm 0.08 \mathrm{~mm}$ process direction

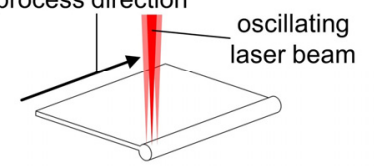

BIAS ID 180465

Fig. 7. Measured thickness (diameter) values of the edge forms at the seven measuring positions along the edge for the "oscillation" strategy (values are based on 70 samples each).

aluminum alloy $\quad$ EN AW 6082-T4 base sheet thickness $\quad 1.0 \mathrm{~mm}$ laser source disk laser TruDisk 8002 laser output power $\quad 1100 \mathrm{~W}$ process speed $\quad 0.8 \mathrm{~m} / \mathrm{min}$ focus diameter $0.2 \mathrm{~mm}$ oscillation frequency oscillation width shielding gas flow

$100 \mathrm{~Hz}$ oscillating front view

$6.3 \mathrm{~mm}$ laser beam

argon $30 \mathrm{l} / \mathrm{min}$

$0.4 \mathrm{~s}$

Woizeschke 2018

BIAS ID 180463

Fig. 5. Front and side view on an exemplary laser formed edge for the "oscillation" irradiation strategy.

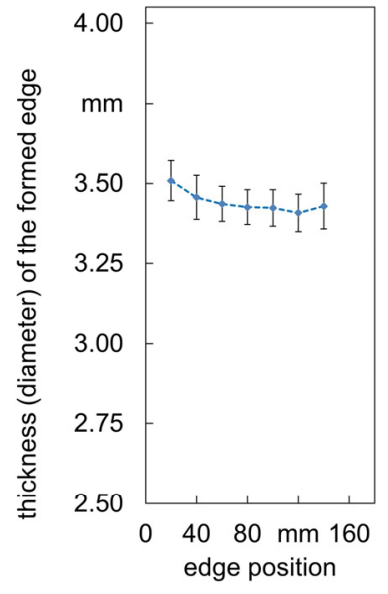

Woizeschke 2018 aluminum alloy EN AW 6082-T4 base sheet thickness $\quad 1.0 \mathrm{~mm}$ laser source disk laser laser output power $\quad 5500 \mathrm{~W}$ process speed $\quad 0.8 \mathrm{~m} / \mathrm{min}$ laser spot diameter $\quad 6.1 \mathrm{~mm}$ focal plane $\quad+16 \mathrm{~mm}$ shielding gas flow argon $20 \mathrm{l} / \mathrm{min}$ preform thickness $3.44 \pm 0.07 \mathrm{~mm}$

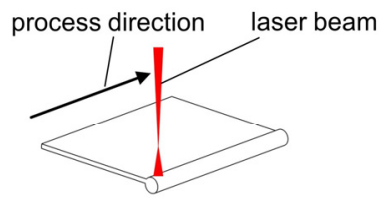

BIAS ID 180464

Fig. 6. Measured thickness (diameter) values of the edge forms at the seven measuring positions along the edge for the "defocused" strategy (values are based on 70 samples each).

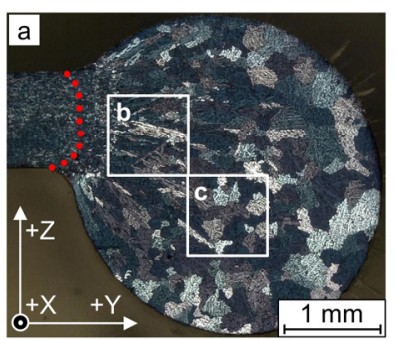

\section{process parameters \\ laser output power process speed \\ laser spot diameter focal plane \\ shielding gas shielding gas flow \\ $5500 \mathrm{~W}$ \\ $0.8 \mathrm{~m} / \mathrm{min}$ \\ $6.1 \mathrm{~mm}$ \\ $+16 \mathrm{~mm}$ \\ argon \\ $20 \mathrm{l} / \mathrm{min}$}

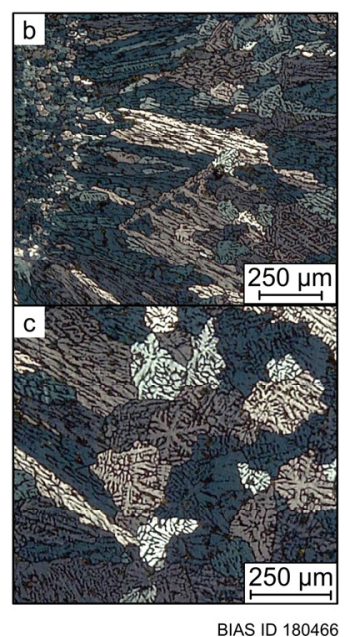

Fig. 8. Exemplary cross-section micrograph (electrolytically etched polish) of a laser formed edge produced by the "defocused" irradiation strategy (red dotted line: fusion line).

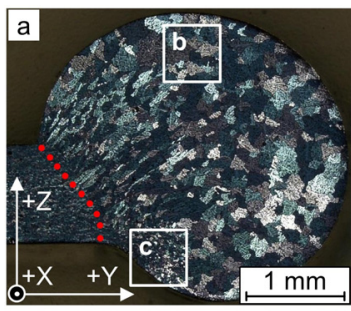

process parameters

laser output power $\quad 1100 \mathrm{~W}$

process speed $\quad 0.8 \mathrm{~m} / \mathrm{min}$

focus diameter $\quad 0.2 \mathrm{~mm}$

oscillation frequency $100 \mathrm{~Hz}$

oscillation width $\quad 6.3 \mathrm{~mm}$

shielding gas argon $20 \mathrm{l} / \mathrm{min}$

initial waiting time $\quad 0.4 \mathrm{~s}$

Woizeschke 2018

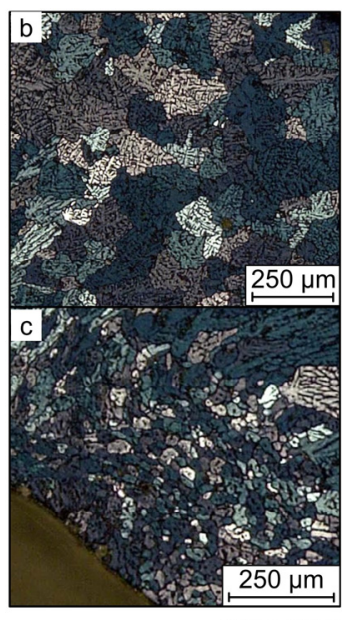

Fig. 9. Exemplary cross-section micrograph (electrolytically etched polish) of a laser formed edge produced by the "oscillation" irradiation strategy (red dotted line: fusion line). 


\subsection{Potential demonstrating forming test}

In order to demonstrate the effect of the increased edge radius of the inner sheet on the bending behavior of the outer sheet in hemming, the effect of a laser formed edge is compared to the behavior in case of a conventional milled sheet edge by sheet forming experiments, see Figure 10. The non-manipulated conventional milled edge of the inner sheet resulted in cracks on the outer surface of the outer sheet when the sheet was completely bent around the inner sheet (Figure 10a). In case of the laser formed edges, crack formation was not observed (Figure 10b).
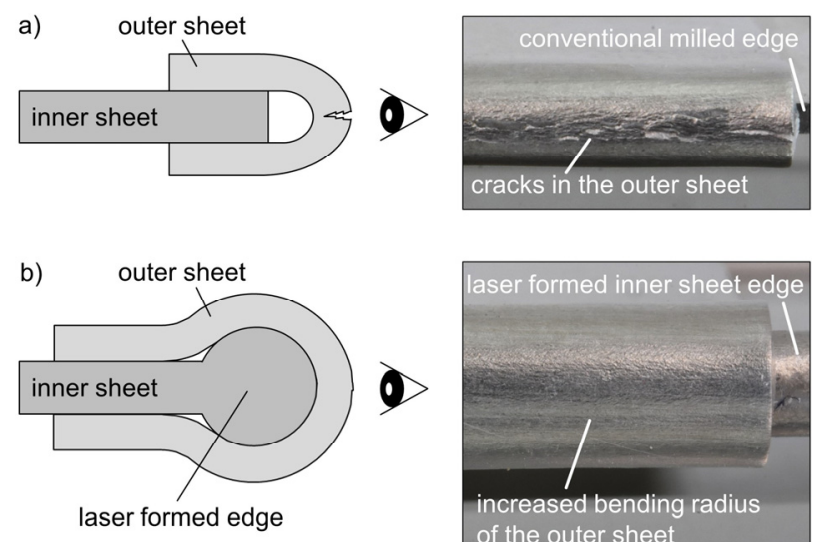

Woizeschke 2018

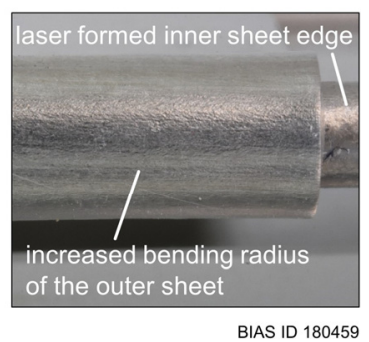

Fig. 10. Sheet forming tests (a) with a non-manipulated conventional milled edge at the inner sheet and (b) with a cylindrically laser formed edge at the inner sheet.

\section{Discussion}

Both irradiation strategies could produce cylindrical shaped edge forms at the edges of $1 \mathrm{~mm}$ thick aluminum sheets. The significantly different process behaviors are caused by the different modes of the applied laser material processes. The comparatively calm process behavior without spatter formation with the defocused laser spot resembles a heat conduction welding process. The laser energy is absorbed on the upper surface. In case of the "oscillation" strategy, the focused laser beam resulted in keyhole formation in the workpiece. The keyhole, a vapor capillary, is formed during laser material processes when the power density reaches a threshold, for example approximately $5 \times 10^{6} \mathrm{~W} / \mathrm{cm}^{2}$ in case of aluminum alloys and solid-state laser sources with wave lengths of $1 \mu \mathrm{m}$. The keyhole formation caused, on the one hand, the high process dynamic in the molten pool with spatter formation in case of beam oscillation. On the other hand, the keyhole formation is responsible for the significantly higher process efficiency of the "oscillation" strategy in comparison with the "defocused" strategy. The needed laser output power for the laser edge forming was five times higher in case of the "defocused" irradiation strategy than in case of beam oscillation with focused laser beam. In typical keyhole (deep penetration) laser welding of aluminum alloys, the absorption can be increased to values over $90 \%$ by the formation of the vapor capillary due to multiple reflections within the keyhole, see [10]. In contrast, the (one-time Fresnel) absorption of aluminum alloys in laser processes like heat conduction welding or laser edge forming with the "defocused" strategy is typically in the range of $5 \%$ to $30 \%$ depending on the surface conditions, the substrate temperature and the alloy composition.

In addition to the process efficiency, the results demonstrate that the irradiation strategy can be used to affect or adjust the orientation of the cylindrical edge form with respect to the plane of the inner sheet. A visible difference between the two irradiation strategies is the orientation of the fusion line within the cross-sections, see Figure 8 and Figure 9. This is probably a main reason for the different edge form position.

The suitability and the advantage of such laser formed edges for hemming processes have been demonstrated by sheet forming experiments, see Figure 10. The cylindrical forms which can be produced by non-contact fast laser melting processes enable the reproducible and precise adjustment of the bending radius by creating a formlocked connection between the outer sheet and the laser formed edge of the inner sheet.

\section{Conclusion}

This study can be concluded as follows:

- Different laser irradiation strategies are suitable to produce reproducible cylindrical forms at aluminum sheet edges with tolerances below $0.1 \mathrm{~mm}$

- The choice of the irradiation strategy affects significantly the process efficiency of the laser edge forming process due to different absorption mechanisms

- The irradiation strategy can be used to affect the position of the edge form with respect to the plane of the inner sheet

- Observed typical cracking of the outer sheets in case of a simple hemming test with conventional milled edges at the inner sheets can be avoided successfully by laser edge forming due to the adjustable increased bending radius.

\section{Acknowledgements}

The authors are grateful for the financial support by the Senatorin für Wissenschaft, Gesundheit und Verbraucherschutz of the country of Bremen.

The 'BIAS ID' numbers are part of the figures and allow the traceability of the results. 


\section{References}

1. N. Le Maoût, S. Thuillier, P. Y. Manach, Engineering Fracture Mechanics 76 (2009) 1202-1214

2. P. Jimbert, I. Eguia, I. Perez, M. A. Gutierrez, I. Hurtado, Journal of Materials Processing Technology 211 (2011) 916-924

3. H. Livatyali, A. Müderrisoğlu, M. A. Ahmetoğlu, N. Akgerman, G. L. Kinzel, T. Altan, Journal of Materials Processing Technology 98 (2000) 41-52

4. S. F. Golovashchenko, Journal of Materials Engineering and Performance 14 (2005) 508-515

5. Z. Hamedon, K. Mori, Y. Abe, Procedia Engineering 81 (2014) 2074-2079

6. M. Blechschmidt, M. Liewald, S. Hoenle, T. Altermann, J. Hesse, patent, DE 102015000981 B4 (2015)

7. Y. Abe, K. Mori, K. Nakagawa, Procedia Engineering 207 (2017) 974-979

8. F. Vollertsen, R. Walther, CIRP Annals Manufacturing Technology 57 (2008) 291-294

9. P. Woizeschke, H. Brüning, F. Vollertsen, Laser Magazin 5 (2015) 22-24

10. Y. Kawahito, N. Matsumoto, Y. Abe, S. Katayama, Journal of Materials Processing Technology 211 (2011) 1563-1568 